\title{
Faktor-Faktor Yang Mempengaruhi Ibu Yang Memiliki Bayi Untuk Mendapatkan Pelayanan Imunisasi Di Puskesmas Bestari Petisah Medan
}

\author{
Meilinda Suntiar Napitupulu ${ }^{1}$, Imam Wahyudi ${ }^{2}$, Eva Ellya Sibagariang ${ }^{3}$ \\ ${ }^{1}$ Universitas Prima Indonesia Jl Sekip Simp. Sikambing, Medan, Indonesia \\ ${ }^{2}$ Universitas Prima Indonesia \\ E-mail: meilindanapitupulu94@gmail.com \\ DOI : https://doi.org/10.35451/jkg.v2i1.252
}

\begin{abstract}
Health service facilities that carry out public health efforts and first-level individual health efforts, with more priority to promotive and preventive efforts, to achieve the highest degree of public health in the working area. The national health system states that immunization is one form of health intervention that is very effective in efforts to reduce infant and under-five mortality rates. This type of research is analytic survey research. Analytic survey is a survey or research that tries to explore and why health phenomena occur. The analytical survey is here to explain the factors that influence mothers who have babies to get immunization services at the Medan Bestari Petisah Health Center. The results of this study have a motivational relationship that affects mothers who have babies to get immunization services at the Bestari Petisah Health Center in Medan, has a family support relationship that affects mothers who have babies to get immunization services at the Bestari Petisah Health Center in Medan, has a knowledge relationship that affects mothers who have babies to get immunization services at Medan's Bestari Petisah Health Center and have a cadre role relationship that affects mothers who have babies to get immunization services at Medan's Bestari Petisah Health Center. To be always active in conducting all puskesmas programs, both long-term and short-term programs
\end{abstract}


Angka kematian bayi secara global masih mengkhawatirkan, dan kawasan Afrika Sub-Sahara menyumbang kematian bayi - meninggal sebelum berusia satu bulan - dalam jumlah tertinggi. "Setiap tahunnya, 2,6 juta bayi di seluruh dunia, tak mampu bertahan hidup selama lebih dari satu bulan. Satu juta di antaranya meninggal saat lahir dalam laporan terbarunya mengenai kematian bayi global (UNICEF, 2018).

Pada tahun 2019 pencapaian Imunisasi Dasar Lengkap hanya mencapai $86,8 \%$ dari target pencapaian sebesar 93\%. Universal Child Immunizatio (UCI) menyatakan bahwa target pencapian imunisasi di daerah pedesaan perlu di tingkatkan agar mencapai target sebesar $92 \%$ di tahun 2019 (Depkes, 2019).

Anak indonesia saat ini banyak yang mengalami kematian pada saat bulan pertama kelahiran (neonatal). Angka kematian anak pada saat bulan pertama kelahiran kurang - lebih mencapai 19/1000 kelahiran. Upaya dalam menurunkan angka kematian anak lebi lanjut terhambat akibat kematian bayi baru lahir. Indonesia yang merupakan salah satu negara berkembang dengan pendapatan menengah telah mengalami penurunan angka kematian pada anak sebagai impact dari meningkatnya pengetahuan ibu, kebersihan rumah dan lingkungan yang baik, pendapatan yang baik dan akses terhadap pelayanan yang mudah. Penyebab dari Kematian anak baru lahir sebagian besar dapat ditanggulangi dengan program - program dan kegiatan - kegiatan peningkatan kesehatan (UNICEF, 2012). republik Indonesia nomor 75 tahun 2014 tentang pusat kesehatan masyarakat, dimana arti dari Puskesmas adalah salah satu upaya peningkatan kesehatan masyarakat dan/ perorangan yang mengutamakan pelayanan promotif dan preventif yang bertujuan untuk peningkatan derajat kesehatan masyarakat Berdasarakan penelitian yang dilakukan oleh Aswadi (2018) menyatakan bahwa masih kurangnya pemanfaatan posyandu hal tersebut di pengaruhi oleh pengetahuan, sikap, dan tindakan keluarga yang masih kurang baik. Keluarga yang jarang membawa anak ke posyandu mengakibatkan orang tua anak tidak memahami alur - alur atau meja - meja dalam posyandu tidak mereka pahami dengan baik. Kurang nya motivasi keluarga berakibat terhadap kurangnya pemanfaatan posyandu.

Sistem kesehatan nasional menyatakan imunisasi adalah salah satu bentuk nyata yang dilakukan pemerintah untuk menurunkan angka kematian bayi dan balita (Hadinegoro, 2013).

Berdasarkan profil kesehatan kota Medan tahun 2016 diketahui bahwa cakupan imunisasi $\mathrm{Hb}<7$ hari sebesar $99,7 \%$, BCG webesar $101,1 \%$, campak sebesar 102,5\%, DPT-HB3/DPT-HB-Hib3 sebesar $100,2 \%$, polio 4 sebesar $99,9 \%$.

Dari survey awal yang peneliti lakukan Puskesmas Bestari Petisah Medan didapatkan data jumlah kunjungan imunisasi dari bulan Januari sampai dengan Desember tahun 2018 sebanyak 3635 anak yang mendapatkan imunisasi dengan jumlah petugas 14 orang dan kader sebanyak 50 orang yang terdiri dari 10 Posyandu. Pada bulan April sampai bulan Juni 2018 terjadi penurunan angka kunjungan pada 
Jurnal Kesehatan Masyarakat \& Gizi, e-ISSN: 2655-0849

Vol. 2 No.1 Edisi Mei-Oktober 2019

https://ejournal.medistra.ac.id/index.php/JKG

$==========================================================+10$
Received: 05 Oktober 2019 :: Accepted: 14 Oktober 2019 :: Published: 31 Oktober 2019

kegiatan program Posyandu

Puskesmas Bestari Petisah Medan. Pada bulan April angka kunjungannya 270 anak, pada bulan Mei turun menjadi 245 kunjungan, dan pada Juni mengalami penurunan kembali dengan angka kunjungan 228 anak. Kemudian peneliti mendapat data kunjungan pasien pada bulan Januari sampai Mei 2019, dimana pada bulan Januari 2019 terdapat sebanyak 137 anak, Februari 2019 sebanyak 112 anak, Maret 2019 sebanyak 104 anak, April 2019 sebanyak 124 anak, dan pada bulan Mei 2019 sebanyak 116 anak. Dari data tersebut terbukti adanya penurunan angka kujungan pada program posyandu di Puskesmas Bestari Petisah Medan. Hal ini harus diperbaiki untuk meningkatkan jumlah kualitas pertumbuhan balita agar tetap terjaga dengan baik.

$$
\text { Peneliti juga melakukan }
$$

pengamatan pada kegiatan program posyandu di Puskesmas Bestari Petisah Medan, dimana peneliti menemukan masalah yaitu kurangnya minat dan kesadaran para ibu untuk mengikuti kegiatan program posyandu yang dilaksanakan oleh Puskesmas Bestari Petisah Medan.

Pada survey awal yang kami lakukan di Puskemas Bestari Medan Petisah, kami berbincang dengan pasien ibu yang memilikibalita. Ketika kami bertanya:

\section{Metode}

.Jenis penelitian ini adalah penelitian survey yang bersifat analitik. 2010). Survei analitik disini untuk menjelaskan factor - faktor yang mempengaruhi ibu yang memiliki bayi untuk mendapatkan pelayanan imunisasi di Puskesmas Bestari Petisah Medan. 


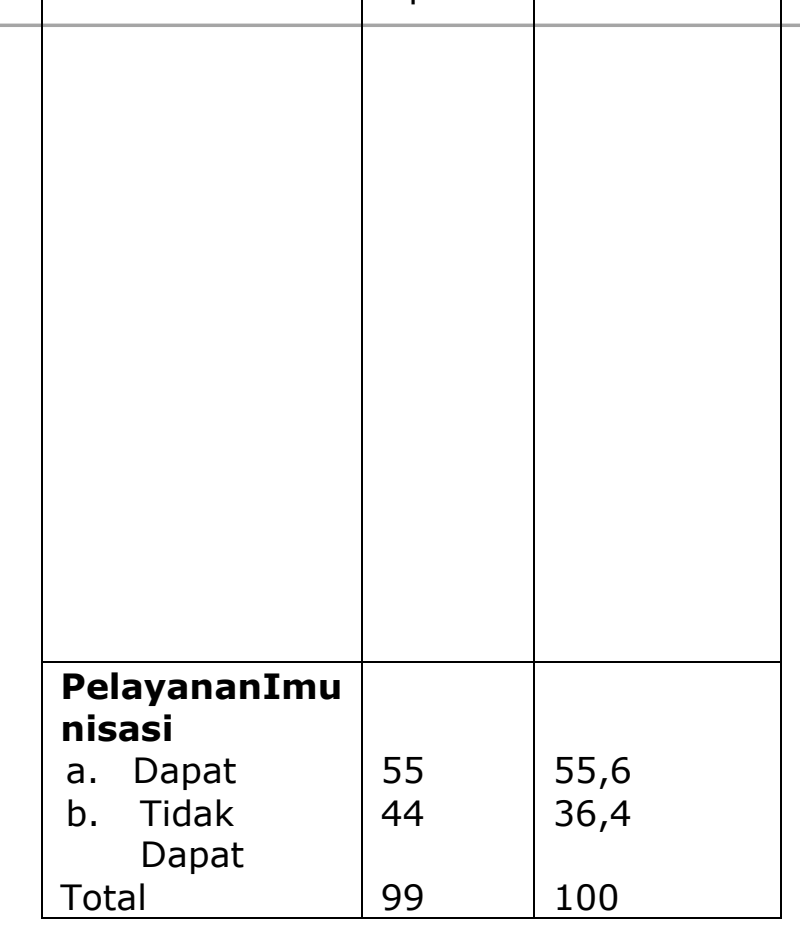

\section{Pembahasan}

\section{Hubungan motivasi yang} mempengaruhiibu yang memilikibayiuntukmendapatkanpela yananimunisasi

PuskesmasBestariPetisah Medan

Berdasarkan hasil ini tentang hubungan motivasi yang mempengaruhi ibu yang memiliki bayi untuk mendapatkan pelayanan imunisasi di Puskesmas Bestari Petisah Medan dengan nilai $p$ value $=0,011$. Kesimpulannya ada hubungan antara hubungan motivasi yang mempengaruhiibu yang memiliki bayi untuk mendapatkan pelayanan imunisasi di Puskesmas Bestari Petisah Medan sejalan dengan hasil penelitian terdahulu.

Berdasarakan penelitian yang dilakukan oleh Aswadi (2018) menyatakan bahwa masih kurangnya pemanfaatan posyandu hal tersebut di pengaruhi oleh pengetahuan, sikap, dan tindakan keluarga yang masih kurang baik. Keluarga yang jarang membawa anak ke posyandu mengakibatkan orang tua anak tidak memahami alur - alur atau meja - meja dalam posyandu tidak mereka pahami dengan baik. Kurang nya motivasi keluarga berakibat terhadap kurangnya pemanfaatan posyandu.

Hasil penelitian Agustina, dkk (2014), motivasi ibu dalam melakukan kunjungan imunisasi pada bayi di Desa Kecamatan JombangKabupaten Jombang, menunjukkan bahwa sebagian besar $(58,1 \%)$ ibu memiliki motivasi positif. Motivasi positif dipengaruh olehusia,pendidikan,pekerjaan dan jarak rumah ke fasilitas kesehatan..

\section{Hubungan dukungan keluarga yang mempengaruhiibu yang} memilikibayiuntukmendapatkanpel ayananimunisasi di PuskesmasBestariPetisah Medan

Berdasarkan hasil penelitian ini tentanghubungan dukungan keluarga yang mempengaruhiibu yang memilikibayiuntukmendapatkanpelayan animunisasi di PuskesmasBestariPetisah Medan diperoleh nilai $p$ value $=0,000$. Kesimpulannya ada hubungan antara hubungan dukungan keluarga yang mempengaruhiibuyang memilikibayiuntukmendapatkanpelayan animunisasi di PuskesmasBestariPetisah Medan.

Hasil penelitian Hidayah., dkk, (2018) menyatakan bahwa faktor yang berhubungan dengan pemberian imuniasi dasar lengkap adalah keterbatasan waktu, dukungan keluarga, informasi imunisasi dan komposisi vaksin.

Hubungan pengetahuan yang mempengaruhiibu yang memilikibayiuntukmendapatkanpela 
Jurnal Kesehatan Masyarakat \& Gizi, e-ISSN: 2655-0849

Vol. 2 No.1 Edisi Mei-Oktober 2019

https://ejournal.medistra.ac.id/index.php/JKG

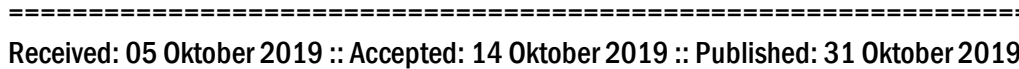

yananimunisasi di di tentang

imunisasi dasar lengkap

PuskesmasBestariPetisah Medan

Berdasarkan

hasil

penelitian ini tentanghubungan

pengetahuan yang mempengaruhiibu

yang

memilikibayiuntukmendapatkanpelayan

animunisasi di PuskesmasBestariPetisah

Medan dengan nilai $p$ value $=0,000$.

Kesimpulannya ada antara hubungan

pengetahuan yang mempengaruhiibu

yang

memilikibayiuntukmendapatkanpelayan

animunisasi di PuskesmasBestariPetisah

Medan menunjukkan penelitian ini

sejalan dengan penelitian terdahulu.

Hasil penelitian Emelya, dkk, (2014) menyatakan bahwa terdapat hubungan antara pengetahuan ibu dan sikap ibut terhadap pemberian imunisasi lengkap pada anak.

\section{Hubungan peran kader yang mempengaruhiibu yang memilikibayiuntukmendapatkanpela yananimunisasi}

PuskesmasBestariPetisah Medan.

Berdasarkanhasilpenelitiani

nitentanghubunganperankader yang

mempengaruhiibu yang

memilikibayiuntukmendapatkanpelayan

animunisasi di PuskesmasBestariPetisah

Medan dengannilai $\mathrm{p}$ value $=0,000$.

Kesimpulannya ada hubungan antara

hubungan peran kader yang

mempengaruhi ibu yang

memilikibayiuntukmendapatkanpelayan

animunisasidi PuskesmasBestariPetisah

Medan.

Hasil penelitian

Septianingtyas (2018), menunjukkan bahwa dukungan kader memiliki pengaruh terhadap imunisasi dasar lengkap dengan $p$-value $=0,013$. Oleh karena itu, direkomendasikan bagi kader untuk meningkatkan pendidikan publik sehingga cakupan imunisasi dasar yang lengkap dapat meningkat

\section{Kesimpulan dan Saran}

Dari hasil penelitian ini adalah terdapat hubungan

Motivasi, pengetahuan, dukungan, dan perankader tentang kunjungan ibu yang memilikibalita pada program posyandu di Puskesmas BestariPetisah Medan.

Bagi puskesmas adalah agar selalu meberi perhatian dan motivasi kepada masyarakat terutama kepada Ibu yang memilikibayi tentang program posyandu. Penyuluhan dan program Imunisasi tetap di jalankan dan di pantau untuk melihat kesuskesan program imunisasi dan dapat menurunkan angka kesakitan pada bayi.

Sedangkan bagiresponden, diharapkan agar ibubalita yang memiliki pengetahuan baik, kurang baik dan tidak baik diharapkan untuk tidak menganggap remeh program posyandu. Jika ibubalitasering mengikuti program posyandu akan meningkatkan kesehatan padabalita.

\section{Daftar Pustaka}

Anonimous. 2010. "Komisi Nasional Lanjut Usia. Pedoman Pelaksana 
Jurnal Kesehatan Masyarakat \& Gizi, e-ISSN: 2655-0849

Vol. 2 No.1 Edisi Mei-Oktober 2019

https://ejournal.medistra.ac.id/index.php/JKG

$==============================================================$
Received: 05 Oktober 2019 :: Accepted: 14 Oktober 2019 :: Published: 31 Oktober 2019

Received: 05 Oktober $2019::$ Accepted: 14
Posyandu Lanjut Usia.

Sulistio, rini. 2017. "Hubungan

Aplonia Amaral, Joko Wiyono, Erlisa Candawati. 2017. "Analisis Faktor Dukungan Keluarga Dengan Keaktifan Lansia Dalam Mengikuti Posyandu Lansia Di Dusun Kehadiran Lansia Dalam Mengikuti Posyandu Di Desa Pagersari Kecamatan Ngantang Kabupaten Malang." 2: 739-48.

Arfan, Iskandar; 2017. "Faktor Frekuensi Kunjungan Lansia Ke Posyandu Lansia Di Kecamatan Pontianak Timur." 3(2): 1-6.

Fatmah. $2012 . \quad$ "Peningkatan Pengetahuan Dan Keterampilan Kader Posbindu Dalam Pengukuran Tinggi Badan Prediksi Lansia, Penyuluhan Gizi Seimbang Dan Hipertensi Studi Di Kecamatan Grogol Petamburan, Jakarta Barat."

Melita, Mardiati, Najib. 2018. "FaktorFaktor Yang Berhubungan Dengan Kunjungan Lansia Ke Posbindu Lansia Di Wilayah Kerja Puskesmas Kelurahan Bintara Kota Bekasi Tahun 2017." 7(4): 158-67.

Nana, Aldriana. 2016. "Faktor - Faktor Yang Berhubungan Dengan Rendahnya Kunjungan Lansia Ke Posyandu Lansia Di Desa Rambah Tengah Utara Wilayah Kerja Puskesmas Rambah Tahun 2015 2016." 2(2): 91-101.

Putri, Mindianata. 2018. "Determinant Factors To Liveliness Of Elderly In." : 213-25.

Sosial, Departemen. 2009. Dukungan Kelembagaan Dalam Kerangka Peningakatan Kesejahteraan Lansia.

Sudarmi. 2014. "Faktor-Faktor Yang Berhubungan Dengan Pemanfaatan." VII(2): 8-14.

Sugiyono. 2017. Metode Penelitian Kuantitatif, Kualitatif Dan R\&D. Bandung: Alfabeta. 